\title{
Reducing resource use and emissions by integrating technology and policy solutions
}

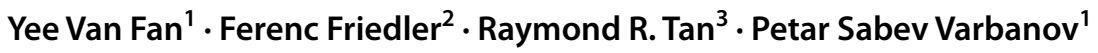 \\ Published online: 20 November 2021 \\ (c) The Author(s), under exclusive licence to Springer-Verlag GmbH Germany, part of Springer Nature 2021
}

Circular economy (CE) is one of the most discussed patterns that aim to tackle the global challenges of resource-saving and emission mitigation. Global efforts are in progress to develop international standards for different aspects of $\mathrm{CE}$ (ISO TC 323 2019). Technology development, process optimisation and waste recovery play an essential part in environmental sustainability. However, they will not work without effective policy design and implementation. Incentives and subsidies are usually needed to enhance the economic feasibility of potential technological solutions and prevent the formation of pollution havens (Fan et al. 2021), especially in the initial stages of the operation. However, good intentions can distort market prices, causing an adverse effect on both the economy and the environment. Careful planning and execution are critical to prevent such outcomes. For example, various recovery and recycling technologies, $\mathrm{CO}_{2}$ capture, utilisation and storage (Manaf et al. 2019), as well as eco-industrial parks, have to be supported by regulatory authorities through taxes or subsidies; where multiple firms are involved in the implementation, schemes for fair and rational allocation of costs and benefits are also essential (Chin et al. 2021).

Social dimensions also determine the effectiveness of technology, but these aspects are inherently difficult to capture. Data analytics could play a part in a practical policy framework by providing insights on public behaviour for data-driven policy regulation (Jiang et al. 2020). Regretfully,

Yee Van Fan

fan@fme.vutbr.cz

1 Sustainable Process Integration Laboratory - SPIL, NETME Centre, Faculty of Mechanical Engineering, Brno University of Technology - VUT Brno, Technická 2896/2, 61669 Brno, Czech Republic

2 Széchenyi István University, Egyetem tér 1, Győr 9026, Hungary

3 Department of Chemical Engineering, De La Salle University, 2401 Taft Avenue, 0922 Manila, Philippines technologists and policymakers generally inhabit two separate worlds that have limited communication with each other (WEF 2019). Sustainable development will only be possible if this science-policy gap can be bridged. Research on both clean technologies and environmental policy can narrow the gap by improving knowledge transfer among key stakeholders. This special issue of Clean Technologies and Environmental Policy is intended to illustrate the symbiosis between "hard" and "soft" approaches to contemporary environmental issues. Thirty-one articles originating from presentations at PRES'20 and SPIL'20 are included in this special issue and illustrate the integration of technology and policy solutions. The focus of the articles ranges from effort in improving the design and process efficiency of various pre-treatment for waste, water network, renewable energy networks to heat recovery for emission and resources reduction, where sustainability assessment is also included. The VSI editors would like to thank the reviewers who engaged in reviewing the papers, the journal publisher, Editor in Chief and Production Editor for supporting this Special Issue.

\section{References}

Chin HH, Varbanov PS, Klemeš JJ, Bandyopadhyay S (2021) Subsidised water symbiosis of eco-industrial parks: a multi-stage game theory approach. Comput Chem Eng 155:107539

Fan YV, Jiang P, Klemeš JJ, Liew PY, Lee CT (2021) Integrated regional waste management to minimise the environmental footprints in circular economy transition. Resour Conserv Recycl $168: 105292$

ISO TC 323 (2019) Stantards by ISO/TC 323 circular economy. www. iso.org/committee/7203984/x/catalogue/. 5 Nov 2021

Jiang P, Fan YV, Zhou J, Zheng M, Liu X, Klemeš JJ (2020) Datadriven analytical framework for waste-dumping behaviour analysis to facilitate policy regulations. Waste Manag 103:285-295

Manaf NA, Weiss G, Abbas A (2019) Relevancy of emission reduction fund (ERF) policy towards large-scale deployment of carbon capture technology in black coal-fired power plant. J Clean Prod 211:1471-1479 
World Economic Forum (WEF) (2019). www.weforum.org/agenda/ 2019/11/we-must-bridge-the-gap-between-technology-and-policy-our-future-depends-on-it/. 1 Nov 2021
Publisher's Note Springer Nature remains neutral with regard to jurisdictional claims in published maps and institutional affiliations. 